\title{
Mass Spectroscopic Approach to Amino Acids Formation Processes by UV Irradiation to Simple Organic Molecules in Aqueous Solution
}

\author{
Masaki Morita, ${ }^{* \dagger}$ Yoshie Harada, ${ }^{*}$ Kunihiro IseKI, ${ }^{*}$ Shunsuke IzUMI, ${ }^{*}$ and Atsunari HIRAYA* \\ *Department of Physical Science, Graduate School of Science, Hiroshima University, \\ 1-3-1 Kagamiyama, Higashihiroshima 739-8526, Japan \\ **Department of Chemistry, Graduate School of Science, Hiroshima University, \\ 1-3-1 Kagamiyama, Higashihiroshima 739-8526, Japan
}

\begin{abstract}
We have studied amino acid formation by UV $(193 \mathrm{~nm})$ irradiation to organic molecules (amines, alcohols and amides) in aqueous solution. Among several types of detected amino acids, small aliphatic amino acids (Gly and $\alpha$-, $\beta$-Ala and $\alpha$-, $\beta-, \gamma$-ABA) were quantitatively identified. Among these small aliphatic amino acids, certain amino acids were formed in its free form, even before hydrolysis, contrary to the results of UV irradiation to a gas mixture of $\mathrm{CO}, \mathrm{NH}_{3}$, and $\mathrm{H}_{2} \mathrm{O}$, where amino acids were hardly detected before hydrolysis. The species distribution of identified amino acids showed a dependence on the starting organic molecules, and also on the presence of ammonia. The formation processes of the identified small aliphatic amino acids were investigated with the aid of electrospray ionization (ESI) MS and MS/MS measurements of photoproducts. Possible formation processes of these amino acid precursors from each starting molecules are proposed. By identifying the amino acid precursor, which has a chiral carbon atom, a new possibility is suggested for asymmetric photosynthesis of amino acid from achiral organic molecules.
\end{abstract}

(Received March 3, 2005; Accepted July 8, 2005)

\section{Introduction}

Since Miller's historical spark-discharge experiment, ${ }^{1}$ a number of studies have been conducted to show possible prebiotic synthesis of amino acids. Consequently, it has been shown that precursors of amino acids can be formed by the irradiation of high-energy photons to a simulated planetary atmosphere, ${ }^{2}$ interstellar dust ${ }^{3}$ and interstellar ice. ${ }^{4,5}$ However, despite the fact that prebiotic synthesis of precursors of amino acids in simulated extraterrestrial environments has been successful, a problem concerning the "homochirality of amino acids on Earth" has been unexplained. In order to find a clue to elucidate this problem, it is necessary to consider which stage of formation processes of amino acids asymmetric fields (like circularly polarized light) contribute to an abiotically enantiomer excess of biomolecules. It seems natural that molecular chirality was introduced not at the first bondformation stage between simple molecules, such as $\mathrm{CO}, \mathrm{N}_{2}$, $\mathrm{NH}_{3}$ and $\mathrm{H}_{2} \mathrm{O}$, because these molecules themselves are achiral. Though it is possible to consider the induced and temporal chirality by the relative placement of these molecules at the bond-formation stage, the degree of chirality should be negligibly small. Therefore, the introduction of molecular chirality should take place at a later stage of photochemical reactions where an organic molecule is converted to another form by an addition or decomposition reaction. As an extreme case for the later introduction of chirality, the asymmetric

† To whom correspondence should be addressed.

E-mail: mmv25001@se.ritsumei.ac.jp photodecomposition of free and racemic amino acid by circularly polarized radiation was also proposed. However, this model seems to be improbable because little free amino acids was observed in extraterrestrial environments, and experimentally identified in photon or high-energy particle irradiation to the simulated interstellar dust. ${ }^{3}$ Finally, addition reactions to simple organic molecules, intermediate species in the course of amino acid formation from simple molecules, remain as the most probable candidate for the "chiralization" step. Therefore, to elucidate the "homochirality of amino acids" problem, it is important to identify the molecular structure of the intermediate products and/or precursors in amino acid formation processes by photo-irradiation to simple organic molecules.

Several studies have been made on observing photoproducts and amino acid precursors produced by abiotic synthesis. Kaneko et al. ${ }^{6}$ observed amino acid after hydrolysis of the product of proton and/or $\gamma$-ray irradiation to gaseous mixtures of $\mathrm{CO}, \mathrm{CH}_{4}$ and $\mathrm{N}_{2}$. They also analyzed unhydrolyzed products of the irradiation by using an elemental composition analysis, GCMS, MALDI-MS, gel filtration, reversed-phase highperformance liquid chromatography (RP-HPLC) and FTIR. However, these unhydrolyzed products were only qualitatively characterized, and precursors of amino acids were not identified. By analyzing photoproducts of the $\mathrm{UV}$ irradiation to simulated interstellar dust consisting of $\mathrm{H}_{2} \mathrm{O}, \mathrm{CH}_{3} \mathrm{OH}, \mathrm{NH}_{3}, \mathrm{CO}$ and $\mathrm{CO}_{2}$ by GC-MS, NMR and IR. Bernstein et al. ${ }^{7}$ suggested that hexamethylenetetramine (HMT), which was the main photoproduct, was a precursor of amino acid, although they did not confirm amino acids formed by hydrolysis. Caro et al. ${ }^{5}$ confirmed the formation of amino acid after hydrolysis of the 
Table 1 Irradiated samples in aqueous solution

\begin{tabular}{cl}
\hline No. & \multicolumn{1}{c}{ Organic molecules and ammonia } \\
\hline 1 & Ethylamine $(25 \%(\mathrm{v} / \mathrm{v}))$, ammonia $(6.25 \%(\mathrm{v} / \mathrm{v}))$ \\
2 & Propylamine $(25 \%(\mathrm{v} / \mathrm{v}))$, ammonia $(6.25 \%(\mathrm{v} / \mathrm{v}))$ \\
3 & Propylamine $(25 \%(\mathrm{v} / \mathrm{v}))$ \\
4 & Butylamine $(25 \%(\mathrm{v} / \mathrm{v}))$, ammonia $(6.25 \%(\mathrm{v} / \mathrm{v}))$ \\
5 & 1-Propanol $(25 \%(\mathrm{v} / \mathrm{v}))$, ammonia $(6.25 \%(\mathrm{v} / \mathrm{v}))$ \\
6 & Propanamide $(10 \mathrm{mM})$, ammonia $(12.5 \%(\mathrm{v} / \mathrm{v}))$ \\
7 & Propanamide $(10 \mathrm{mM})$ \\
8 & Butanamide $(10 \mathrm{mM})$ \\
\hline
\end{tabular}

photoproducts formed by almost the same irradiation condition as Bernstein et al., then demonstrated that HMT is not the precursor of amino acids. As a matter of fact, precursors of amino acids in UV irradiation experiments have never been identified.

To identify the precursors of amino acids, not simple molecules, such as $\mathrm{CO}, \mathrm{NH}_{3}, \mathrm{H}_{2} \mathrm{O}$, but organic molecules (amine ${ }^{5}$, amide ${ }^{8}$ and alcohol $^{8}$ ) having two to four carbon atoms were used as irradiated samples in the present work. As discussed above, UV photo-reactions of simple organic molecules must be important as the reaction stage to introduce chirality to the molecular system. We also analyzed not all amino acids formed, but only small aliphatic amino acids that are mainly produced in many irradiation experiments. ${ }^{2-6}$ These amino acids were quantitatively identified. Formation processes of identified small aliphatic amino acids were estimated from mass spectroscopic analysis of photoproducts. Though GC-MS has been used widely ${ }^{5-7,9}$ for mass analysis, it is difficult to identify products because of the fragmentation of derivatized products by electron impact. Therefore we selected ESI-MS ${ }^{10}$ spectroscopy, in which electrospray ionization (ESI) makes it possible to ionize a molecule without the fragmentation, and does not require derivatization of molecule. Thus, raw products can be observed in ESI-MS. Furthermore, information about the molecular structures of photoproducts can be obtained by using the MS/MS method. ${ }^{11}$

\section{Experimental}

\section{UV irradiation}

Aqueous solutions of achiral organic molecules (see materials section) in a quartz cell (optical length, $5 \mathrm{~mm}$; volume, $600 \mu \mathrm{l}$ ) were irradiated by linearly polarized UV from an ArF excimer laser $(\lambda, 193 \mathrm{~nm} ; 5 \mathrm{~Hz}$; pulse energy, $10-20 \mathrm{~mJ})$ at room temperature. The irradiation time was $3 \mathrm{~h}$ for almost all samples, except for the ethylamine sample. The photon dose was estimated by the pulse energy of the laser, and absorbance of the samples spanned from 30 to $80 \times 10^{19}$ photons.

\section{Amino acid analysis}

The irradiated materials were divided into some portions, and these portions were evaporated in vacuum. One portion was hydrolyzed with $6 \mathrm{M} \mathrm{HCl}$ at $110^{\circ} \mathrm{C}$ for $24 \mathrm{~h}$. After hydrolysis, 6 $\mathrm{M} \mathrm{HCl}$ was evaporated to dryness. Both hydrolyzed and unhydrolyzed portions after being dried were dissolved in 200 $\mu 1$ of Milli-Q water, and then analyzed with a RP-HPLC system where a precolumn derivatization with $o$-phthalaldehyde and $N$ acetyl-L-cysteine (OPA/NALC) ${ }^{12}$ was applied. A $50 \mu \mathrm{l}$ of sample solution was mixed with $100 \mu \mathrm{l}$ of OPA/NALC (12 $\mathrm{mM} / 12 \mathrm{mM}$ ) reagent in a water/methanol (100:1) solution, in

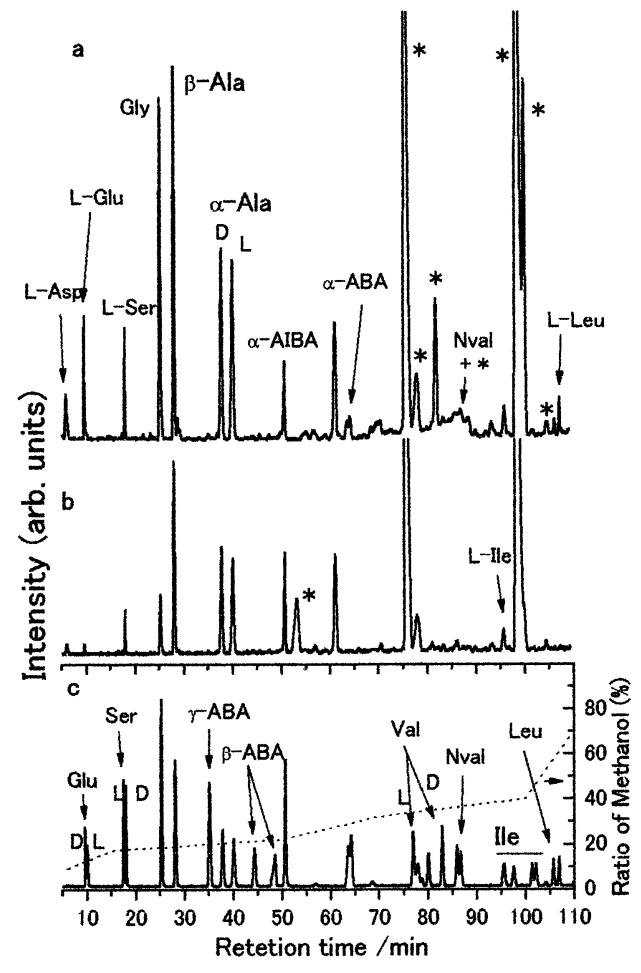

Fig. 1 Chromatograms of the hydrolyzed (a) and unhydrolyzed (b) portions of the products formed by the UV irradiation to the propanamide aqueous solution. (c) Chromatogram of standard amino acids and the elution gradient. Dotted line, ratio of methanol; AIBA, aminoisobutyric acid; ABA, aminobutyric acid; *, unidentified peaks.

which the OPA/NALC solution was adjusted to $\mathrm{pH} 10.5$ by $\mathrm{KOH}$ and boric acid. After $2 \mathrm{~min}$ of reaction time, a volume of $60 \mu \mathrm{l}$ was injected into the HPLC system. The HPLC system used was composed of a quaternary pump (JUSCO PU2089), a column oven (JUSCO CO2065) maintained at $40^{\circ} \mathrm{C}$ and a fluorescence detector (JUSCO FR2025) with excitation at 455 $\mathrm{nm}$ and emission at $335 \mathrm{~nm}$. The column used was an ODS C18 (MERCK Purospher RP-18e $5 \mu \mathrm{m}, 4 \mathrm{~mm}$ i. d. $\times 250 \mathrm{~mm}$ ). This HPLC was possible to resolve and identify of all kinds of amino acid studied as the derivatized amino acid diastereoisomers by using appropriate elution gradient (Fig. 1c). A $10 \mathrm{mM}$ sodium phosphate aqueous solution ( $\mathrm{pH} \mathrm{6.9)}$ and methanol were used as the eluent. Figure 1c shows a chromatogram of standard amino acids and the ratio of methanol of the eluent. The flow-rate of the eluent was 0.7 $\mathrm{ml} / \mathrm{min}$. The amounts of each amino acid were estimated from peak area of each chromatogram compared to the standard amino acids.

Since protein amino acids, such as Gly, L-Ser, L-Leu, were detected in the hydrolyzed and unhydrolyzed portions due to contamination at evaporation, the true amount of Gly produced by UV irradiation was estimated by subtracting the amount of Gly of an unirradiated sample. Other amino acids were quantified by the amount of D-amino acid, assuming that a racemic body is produced by linearly polarized radiation. Although fungous ${ }^{13}$ and bacterial sources of D-amino acids exist, they are very rare, and would have little possibility to contaminate our samples. Actually, no D-amino acids were observed in unirradiated samples. Non-protein amino acids and D-amino acids and other peaks were not detected by RP-HPLC for unirradiated samples. 
Table 2 Amount of aliphatic amino acids formed by UV irradiation to each starting material

\begin{tabular}{|c|c|c|c|c|c|c|c|c|c|c|c|}
\hline Starting material & Dose $^{a}$ & Fraction & Gly & $\beta$-Ala & $\alpha$-Ala & $\gamma-\mathrm{ABA}$ & $\beta$-ABA & $\alpha$-ABA & $\beta$-AIBA & Nval & Other \\
\hline \multirow[t]{2}{*}{ 1. $\mathrm{C}_{2} \mathrm{H}_{5} \mathrm{NH}_{2}, \mathrm{NH}_{3}$} & \multirow[t]{2}{*}{76} & Unhydrolysis & 0.4 & 0.1 & 1.2 & - & 0.3 & - & - & - & \\
\hline & & Hydrolysis & 6.4 & 0.4 & 2.7 & 0.2 & 2.3 & - & - & - & \\
\hline \multirow[t]{2}{*}{ 2. $\mathrm{C}_{3} \mathrm{H}_{7} \mathrm{NH}_{2}, \mathrm{NH}_{3}$} & \multirow[t]{2}{*}{35} & Unhydrolysis & 0.0 & 0.1 & 0.4 & 0.2 & - & 2.3 & 0.4 & - & \\
\hline & & Hydrolysis & 1.1 & 7.1 & 3.3 & 0.6 & - & 3.4 & 0.7 & - & \\
\hline \multirow[t]{2}{*}{ 3. $\mathrm{C}_{3} \mathrm{H}_{7} \mathrm{NH}_{2}$} & \multirow[t]{2}{*}{33} & Unhydrolysis & 0.0 & t.r. & t.r. & 0.1 & - & 2.2 & 0.3 & - & \\
\hline & & Hydrolysis & 0.0 & 0.4 & 0.1 & 0.1 & - & 2.3 & 0.3 & - & Ser (t.r.) \\
\hline \multirow{2}{*}{ 4. $\mathrm{C}_{4} \mathrm{H}_{9} \mathrm{NH}_{2}, \mathrm{NH}_{3}$} & \multirow[t]{2}{*}{34} & Unhydrolysis & 0.0 & 0.1 & t.r. & t.r. & 0.4 & 1.1 & - & $<2$ & \\
\hline & & Hydrolysis & 0.0 & 0.1 & 0.1 & 0.1 & 0.9 & 1.3 & 0.1 & $<5$ & \\
\hline \multirow{2}{*}{ 5. $\mathrm{C}_{3} \mathrm{H}_{7} \mathrm{OH}, \mathrm{NH}_{3}$} & \multirow[t]{2}{*}{33} & Unhydrolysis & 0.0 & 0.1 & 0.4 & - & - & - & - & - & \\
\hline & & Hydrolysis & 0.4 & 1.4 & 1.8 & - & - & 0.8 & 0.1 & - & \\
\hline \multirow[t]{2}{*}{ 6. $\mathrm{C}_{2} \mathrm{H}_{5}(\mathrm{C}=\mathrm{O}) \mathrm{NH}_{2}, \mathrm{NH}_{3}$} & \multirow[t]{2}{*}{34} & Unhydrolysis & 0.0 & t.r. & 0.3 & - & - & 1.7 & - & - & \\
\hline & & Hydrolysis & 2.4 & 1.7 & 5.0 & - & - & 2.0 & - & - & \\
\hline \multirow[t]{2}{*}{ 7. $\mathrm{C}_{2} \mathrm{H}_{5}(\mathrm{C}=\mathrm{O}) \mathrm{NH}_{2}$} & \multirow[t]{2}{*}{37} & Unhydrolysis & 0.0 & 2.2 & 2.9 & - & - & - & t.r. & t.r. & \\
\hline & & Hydrolysis & 1.7 & 5.3 & 6.1 & - & - & 0.7 & t.r. & $<0.6$ & Ser (t.r.) \\
\hline \multirow[t]{2}{*}{ 8. $\mathrm{C}_{3} \mathrm{H}_{7}(\mathrm{C}=\mathrm{O}) \mathrm{NH}_{2}$} & \multirow[t]{2}{*}{36} & Unhydrolysis & 0.0 & 0.2 & 0.1 & 0.3 & 1.2 & 0.8 & 0.1 & $\sim 0.6$ & \\
\hline & & Hydrolysis & 0.7 & 0.5 & 0.3 & 2.1 & 5.0 & 1.6 & 0.2 & $\sim 1$ & \\
\hline
\end{tabular}

Amounts in nmol units. a. Dose in $10^{19}$ photons units. t.r.: trace level.

\section{Mass analysis}

In order to identify the photoproducts formed by UV irradiation, some unhydrolyzed samples were analyzed with the QSTAR ESI-MS ${ }^{14}$ system (Applied Biosystems Inc.), which consists of the ESI source, a quadrupole mass filter, a LINAC collision cell and high-resolution RTOF-MS. ESI-MS operated in the positive ion detection mode. A mass resolution higher than 10000 allows us to identify the molecular formula of ions in low mass range (below $m / z \sim 300$ ). This ESI-MS system is able to measure the MS/MS spectrum of the fragment ions formed by CID (Collision Induced Dissociation) of target ion. By measuring the MS/MS spectrum, information on the molecular structure of a molecular ion detected in ESI-MS is obtained. Sample solutions (Nos. 2, 5, 6; see material section) prepared by dissolving a dried sample in $1 \%$ acetic acid were injected to the ESI-MS system. All ESI-MS spectra shown in this paper were obtained after subtracting the background signal of the ESI-MS system.

\section{Materials}

Aqueous solutions of achiral molecules having a different functional group and/or carbon number, with or without ammonia were irradiated. Table 1 gives the details of irradiated aqueous solutions. Each material was a commercial product and used without further purifications.

\section{Results and Discussion}

\section{Yield of amino acids}

Figure 1 shows HPLC chromatograms of hydrolyzed and unhydrolyzed portions of the product obtained by irradiation to the propanamide aqueous solution, and of standard amino acids. Amino acids, such as L-Ser, Gly, $\alpha$ - and $\beta$-Ala, were identified in both portions. In order to quantitatively compare the amount of amino acids before hydrolysis, $\alpha$-AIBA was added after irradiation as an internal standard, because $\alpha$-AIBA was not produced in all irradiated samples. Rather, many peaks at a long retention time, especially dominant peaks at 77 and 99 min, do not correlate to general amino acids, and were unidentified in the present work. All of L-Asp, L-Glu, L-Ser, LIle, L-Leu and parts of Gly and L- $\alpha$-Ala are due to contaminations. Thus, $\alpha$ - and $\beta$-Ala were dominant amino acids in both portions. Large aliphatic amino acids, such as Val, Nval, Leu and Ile, were hardly quantified because many peaks were overlapped for all irradiated samples, as for natural sample. ${ }^{15}$ However, the amounts of these aliphatic amino acids, except for Nval, were very small compared to the identified amino acids. Basic amino acids and aromatic amino acids were not studied because the aim of the present investigation was the formation processes of small aliphatic amino acids that are mainly produced in many irradiation experiments. ${ }^{2-6}$ Amounts in nmol units of small aliphatic amino acid mainly detected both for hydrolyzed and unhydrolyzed portions are summarized in Table 2. It is noteworthy that several amino acids, such as $\alpha$ ABA from propylamine, were clearly detected even before hydrolysis, contrary to the results of UV irradiation to the gas mixture of $\mathrm{CO}, \mathrm{NH}_{3}$, and $\mathrm{H}_{2} \mathrm{O}$, where amino acids were hardly detected before hydrolysis.

The correlation between the starting material and the amino acid species formed by UV irradiation is discussed below. Also, the formation processes of the observed small aliphatic amino acids are discussed with the aid of the ESI-MS spectrum.

Mass spectrometric analysis of photoproducts from propylamine

For a propylamine aqueous solution with ammonia (No. 2), the mainly produced amino acids after hydrolysis were $\alpha$-Ala, $\beta$-Ala and $\alpha$-ABA. Among these amino acids, $\alpha$ - and $\beta$-Ala were dominant only with ammonia, while $\alpha$-ABA was produced both with and without ammonia (No. 3). It is noteworthy that $\alpha$-ABA was formed before hydrolysis with an appreciable amount, regardless of the presence of ammonia.

Figure 2 shows the ESI-MS and MS/MS spectra of the products by UV irradiation to a propylamine aqueous solution with ammonia (No. 2). Peak appeared at 117.13 was assigned to either $\mathrm{C}_{6} \mathrm{H}_{17} \mathrm{~N}_{2}{ }^{+}$or $\mathrm{C}_{7} \mathrm{H}_{17} \mathrm{O}^{+}$from MS spectrum. Owning to the high mass resolution, other molecular ions, such as $\mathrm{C}_{4} \mathrm{H}_{13} \mathrm{~N}_{4}{ }^{+}$ $(m / z=117.11)$ and $\mathrm{C}_{5} \mathrm{H}_{13} \mathrm{~N}_{2} \mathrm{O}^{+}(\mathrm{m} / z=117.10)$ can be excluded. In order to determine the structure of the ion appearing at 117.13, the MS/MS spectrum was measured (Fig. 2(b)). Fragment ions appearing at 100.11 and 58.06 were observed. Fragments ions appearing at 100.11 and 58.06 were uniquely assigned to be $\mathrm{C}_{6} \mathrm{H}_{14} \mathrm{~N}^{+}(\mathrm{m} / \mathrm{z}=100.11)$ and $\mathrm{C}_{3} \mathrm{H}_{8} \mathrm{~N}^{+}(\mathrm{m} / \mathrm{z}=58.06)$, respectively. Because fragment ions have no $\mathrm{O}$ atom, the parent ion appearing at 117.13 can be assigned as $\mathrm{C}_{6} \mathrm{H}_{17} \mathrm{~N}_{2}{ }^{+}$. Furthermore, the molecular structure of $\mathrm{C}_{6} \mathrm{H}_{17} \mathrm{~N}_{2}{ }^{+}$is estimated 

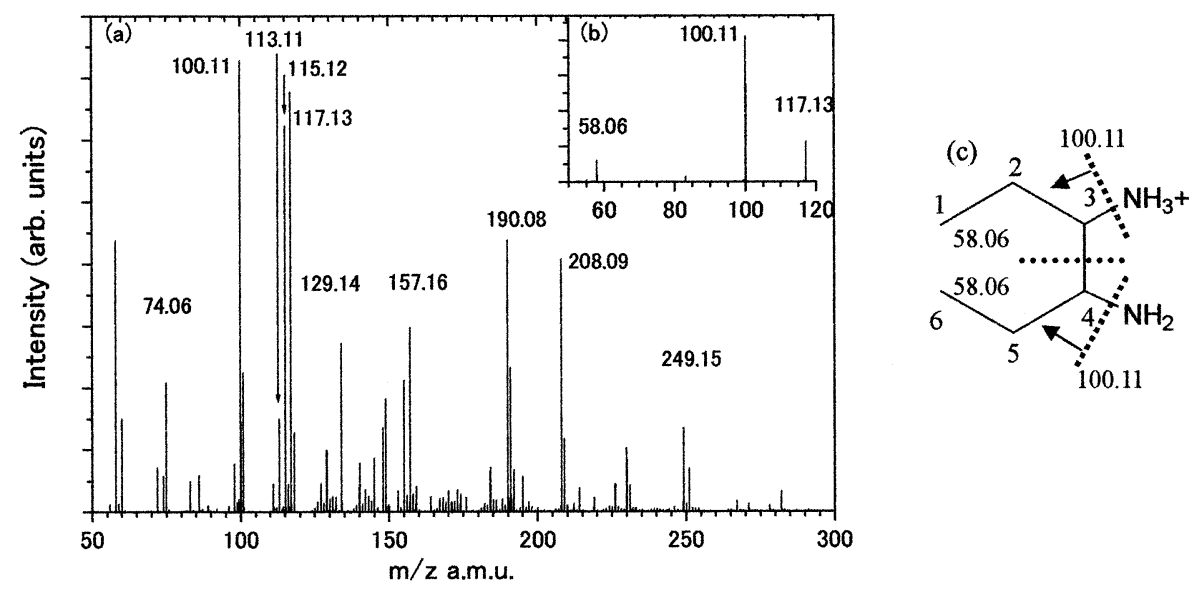

Fig. 2 (a) ESI-MS spectrum of photoproducts of the irradiation to the propylamine aqueous solution with ammonia, (b) MS/MS spectrum targeted to 117.13 in ESI-MS, and (c) molecular structure of ion appearing at 117.13 (N-protonated 3,4-diaminohexane) and fragmentation pattern to give the observed MS/MS peaks. Assigned molecular formulas; 74.06, propanamide ion; 100.11, $\mathrm{C}_{6} \mathrm{H}_{16} \mathrm{~N}^{+}$; 113.11, $\mathrm{C}_{6} \mathrm{H}_{13} \mathrm{~N}_{2}+;$;15.12, $\mathrm{C}_{6} \mathrm{H}_{15} \mathrm{~N}_{2}^{+} ; 117.13, \mathrm{C}_{6} \mathrm{H}_{17} \mathrm{~N}_{2}+129.14, \mathrm{C}_{7} \mathrm{H}_{17} \mathrm{~N}_{2}^{+} ; 157.16, \mathrm{C}_{6} \mathrm{H}_{15} \mathrm{~N}_{2}+\mathrm{C}_{3} \mathrm{H}_{6}^{+}$; 190.08, $\mathrm{C}_{10} \mathrm{H}_{12} \mathrm{~N}_{3} \mathrm{O}^{+} ; 208.09,\left[\mathrm{C}_{10} \mathrm{H}_{12} \mathrm{~N}_{3} \mathrm{O}+\mathrm{OH}\right]^{+} ; 249.15,\left[\mathrm{C}_{10} \mathrm{H}_{12} \mathrm{~N}_{3} \mathrm{O}+\text { propylamine }\right]^{+}$.

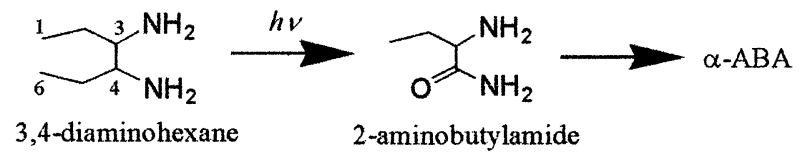

Scheme 1 Formation process of $\alpha$-ABA from propylamine via dimerized 3,4-diaminohexane.

from the MS/MS spectrum. A possible molecule for $\mathrm{C}_{6} \mathrm{H}_{17} \mathrm{~N}_{2}{ }^{+}$ is N-protonated 3,4-diaminohexane, which can be formed by dimerization of propylamine at its $\mathrm{C} 1$ (adjacent to $\mathrm{NH}_{2}$ ) position. Figure 2 (c) shows the molecular structure of $\mathrm{N}$ protonated 3,4-diaminohexane and possible fragmentation patterns by CID, estimated from the MS/MS spectrum. C3-N or $\mathrm{C} 4-\mathrm{N}$ and $\mathrm{C} 3-\mathrm{C} 4$ bond scissions of this molecule lead to fragment ions at 100.11 and 58.06, respectively. Therefore, the molecular ion at 117.13 is assigned as N-protonated 3,4diaminohexane. In fact, not only 3,4-diaminohexane but also two other dimer forms of propylamine, 2-methyl-3aminopentylamine (dimerized at $\mathrm{C} 1$ and $\mathrm{C} 2{ }^{\prime}$ ) and 1, 4diaminohexane (dimerized at $\mathrm{C} 1$ and $\mathrm{C}^{\prime}$ ), are possible to produce these fragment ions.

The ion appearing at 100.11 in ESI-MS (Fig. 2(a)) should be the same ion assigned above as a fragment ion from 117.13. It should be noted that the neutral form of the ion observed at 100.11 in ESI-MS is directly produced by UV irradiation. The peak appearing at 115.12 in ESI-MS is assigned to unsaturated dimerized propylamine. In the MS/MS spectrum of 115.12, fragment ions with $\mathrm{m} / \mathrm{z}=73.08 \quad\left(\mathrm{H}_{2} \mathrm{NC}_{2} \mathrm{H}_{4} \mathrm{CH}=\mathrm{NH}_{2}{ }^{+}\right.$or $\left.\mathrm{HN}=\mathrm{CHC}_{2} \mathrm{H}_{4} \mathrm{NH}_{3}^{+}\right), 60.08\left(\mathrm{C}_{3} \mathrm{H}_{7} \mathrm{NH}_{3}^{+}\right)$and $56.05\left(\mathrm{C}_{3} \mathrm{H}_{4}=\mathrm{NH}_{2}{ }^{+}\right)$ were detected. Molecular ions, which can produce these fragment ions, are considered to be the iminium ion $\left(\mathrm{R}-\mathrm{C}=\mathrm{N}-\mathrm{R}^{\prime}\right)$ formed by the dimerization of propylamine at $\mathrm{N}$ and $\mathrm{C}^{\prime}\left(\mathrm{Cl}^{\prime}\right.$, $\mathrm{C}^{\prime}$ or $\mathrm{C}^{\prime}$ ), such as $\mathrm{C}_{3} \mathrm{H}_{7} \mathrm{~N}=\mathrm{CHC}_{2} \mathrm{H}_{4} \mathrm{NH}_{3}{ }^{+}$and $\mathrm{C}_{3} \mathrm{H}_{7} \mathrm{~N}^{+} \mathrm{H}_{2} \mathrm{CH}\left(\mathrm{CH}_{2}\right) \mathrm{CH}=\mathrm{NH}$. Imines, the neutral form of these iminium ions, are known to be stable under excess ammonia, though generally unstable in water. The detected amount of iminium ions can be considered as the remaining part of imines after partial hydrolysis in the $1 \%$ acetic acid solution for the ESI-MS measurements. The ion appearing at 74.06 is readily assigned as a propanamide ion. Ions corresponding to the peaks at 190.08, 208.09 and 249.15 can be assigned as molecular ions containing nitrogen heterocycles, though their exact structures are not determined.

\section{Formation processes of amino acids from propylamine}

The formation processes of amino acid and their precursors for UV irradiation to a propylamine solution can be inferred by considering the mass patterns in ESI-MS and the distributions of amino acids for different conditions, such as with or without ammonia, before or after hydrolysis. First, the suppression of $\alpha$ - and $\beta$-Ala formation in the solution without ammonia implies that their precursor is not formed, or unstable without ammonia. Among assigned products in ESI-MS for propylamine aqueous solution with ammonia, imines match to this condition that being unstable without excess ammonia. The hydrolysis of the two imines above gives $\mathrm{C}_{3} \mathrm{H}_{7} \mathrm{NH}_{2}+$ $\mathrm{O}=\mathrm{CHC}_{2} \mathrm{H}_{4} \mathrm{NH}_{2}$ or $\mathrm{C}_{3} \mathrm{H}_{7} \mathrm{NHCH}\left(\mathrm{CH}_{2}\right) \mathrm{CH}=\mathrm{O}+\mathrm{NH}_{3}$. The former aldehyde may give $\beta$-Ala, but not $\alpha$-Ala. $\alpha$-Ala can be formed from $\mathrm{C}_{2} \mathrm{H}_{5} \mathrm{CH}=\mathrm{NCH}\left(\mathrm{CH}_{3}\right) \mathrm{CH}=\mathrm{N}$, which is a dimerized propylamine having two $\mathrm{C}=\mathrm{N}$ bonds. A small peak of its molecular ion was observed at $\mathrm{m} / z=113.11$, which is assigned to $\mathrm{C}_{6} \mathrm{H}_{13} \mathrm{~N}_{2}{ }^{+}$, but this molecular structure with $m / z=113.11$ was not decided. It is also considered that $\alpha$ - and $\beta$-Ala are produced from polymerized a propylamine having $\mathrm{C}=\mathrm{N}$ bonds. Although trimerized propylamine was not observed in ESI-MS, molecular ions having a greater carbon number than the dimer and unsaturated bonds were observed at 129.14 and 157.16 in ESI-MS (Fig. 2(a)). Thus, the formation of $\alpha$ - and $\beta$-Ala is considered to be related to polymerized propylamine having imine bonds.

Second, $\alpha$-ABA formation before hydrolysis in a propylamine solution, irrespectively with or without ammonia, suggests Scheme 1. The first step is the radical dimerization of propylamine to form 3,4-diaminohexane, which is actually identified in ESI-MS as an intermediate species formed by UV irradiation to the propylamine solution of ammonia water. 2Aminobutanamide can be formed from 3,4-diaminohexane by 


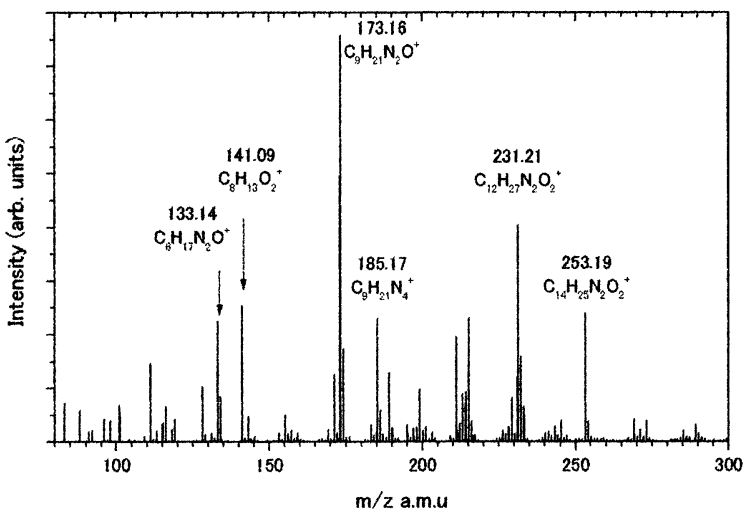

Fig. 3 ESI-MS spectrum of products of UV irradiation to the 1propanol aqueous solution with ammonia.

$\mathrm{C} 2-\mathrm{C} 3$ or $\mathrm{C} 4-\mathrm{C} 5$ bond scission, followed by oxidation at $\mathrm{C} 3$ or C4. Further oxidation of 2-Aminobutanamide at the amide carbon terminated as $\alpha$-ABA. All of the steps in this scheme are considered as UV photo-induced reactions. It is noteworthy that 2-Aminobutanamide is a chiral molecule.

Third, a small amount of $\gamma$-ABA, detected for propylamine solution, irrespectively with or without ammonia, could be formed from 1, 4-diaminohexane, which is one of the position isomers of 3,4-diaminohexane to form $\alpha$-ABA, via 4Aminobutanamide. As for $\beta$-AIBA, it can be formed from 2 methyl-3-aminopentylamine, which is the other position isomers of 3,4-diaminohexane. It should be mentioned why both $\alpha$-ABA and 2-Aminobutanamide were not observed in the ESI-MS spectrum. This was because amino acid and amino acid amide are hardly detected in the ESI-MS because of two ionic states, ${ }^{13}$ a positive ion and a zwitter ion (having both positive and negative parts), of these compounds are intermingled in $1 \%$ acetic acid aqueous solution $(\mathrm{pH} \sim 3)$ and/or because the amounts of alanine amide and $\alpha$-ABA would be very small relative to the molecular ions mainly observed in Fig. 2(a)

The percentage of the amount of $\alpha$-ABA produced before hydrolysis compared to that after hydrolysis in a propylamine aqueous solution with ammonia (68\%) is smaller than that in propylamine aqueous solution without ammonia (96\%) (see Table 2). This difference can be explained as follows. For the propylamine aqueous solution with ammonia, a part of 2 aminobutanamide, which is precursor of $\alpha$-ABA, is not hydrolyzed because amide compounds are hardly hydrolyzed with excess ammonia.

Regarding molecular ions appearing at 190.08, 208.09 and 249.15 in ESI-MS, since the nitrogen heterocyclic compounds are known not to produce amino acids by hydrolysis, these molecules were unlikely to be associated with the formation of aliphatic amino acids.

Formation processes of amino acids from ethylamine and butylamine

For an ethylamine aqueous solution with ammonia (No. 1), Gly, $\alpha$-Ala and $\beta$-ABA were mainly produced after hydrolysis. As discussed concerning the amino acid formation processes from propylamine, it is considered that Gly and $\alpha$-Ala are formed from dimerized ethylamine having a $\mathrm{C}=\mathrm{N}$ bond and 2 amino propanamide via butane-2, 3-diamine, respectively. $\beta$ ABA can be formed from 3-amino butylamide via butane-1,3diamine. For a butylamine aqueous solution with ammonia (No. 5), the formation processes of $\alpha-, \beta$ - and $\gamma$-ABA and Nval
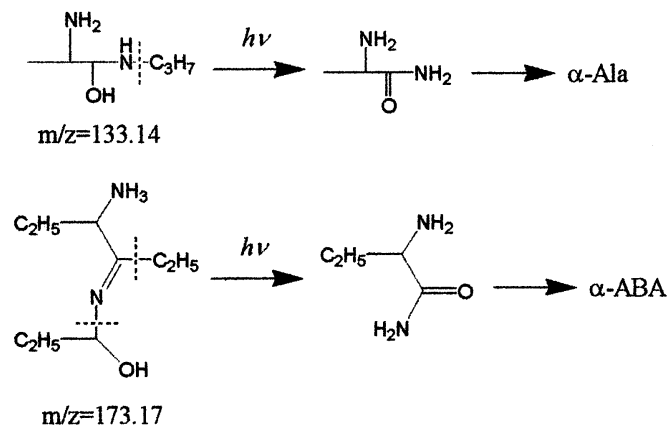

Fig. 4 The neutral form of molecular ions appeared at 133.14 and 173.17 in MS spectrum, and formation processes of amino acids from these molecules.

produced after hydrolysis can also be explained as discussed for amino acid formation processes from propylamine.

The reaction passes to form amino acid species having one more carbon atom than starting molecules, $\alpha$-Ala from ethylamine and Nval from butylamine, can be similar to the formation process of $\alpha$-ABA from propylamine. This is justified from the fact that these three amino acids were formed in appreciable amount, even before hydrolysis.

\section{Formation processes of amino acids from propanol}

The distribution of aliphatic amino acids after hydrolysis of the UV irradiated propanol aqueous solution with ammonia shows a similar distribution in the propylamine aqueous solution with ammonia (see Table 2). In contrast to the similarity between amine and alcohol in amino acid products after hydrolysis, no amino acids were detected for alcohol before hydrolysis.

The ESI-MS spectrum of products of the UV irradiation to the propanol aqueous solution with ammonia is shown in Fig. 3. The molecular ions in Fig. 3 are different from those appearing in the propylamine aqueous solution with ammonia (Fig. 2(a)). Figure 4 shows possible molecular structures estimated from MS/MS for peaks at $m / z=133.14$ and 173.17. For 133.14 and 173.17, possible formation processes of detected amino acids $(\alpha$-Ala and $\alpha$-ABA) from these molecular ions are also shown in Fig. 4. For the neutral molecule corresponding to the ion appeared at 133.14, UV induced bond scission at the dotted lines produce amino acid amides that can be hydrolyzed to $\alpha$ Ala. $\beta$-Ala can be formed from the constitutional isomer in which the amino group $\left(-\mathrm{NH}_{2}\right)$ is connected to the terminal carbon of the molecule $(m / z=133.14)$ shown in Fig. 4 . $\alpha$-ABA can be formed by UV-induced bond scissions of the neutral molecule associated with the ion appearing at 173.17 in the ESIMS spectrum. In UV irradiation to a propanol aqueous solution with ammonia, all amino acids are produced by way of the amino acid amide from aminoalcohol, because little amounts of amino acids are produced before hydrolysis.

\section{Formation processes of amino acids from amide}

Amino acid species produced from amide aqueous solutions with or without ammonia (Nos. 6-8) were aliphatic amino acids having the same number of carbon atoms to the starting amide compounds (see Table 2). For propanamide and butanamide aqueous solutions (Nos. 7, 8), $\alpha$-, $\beta$-Ala, and $\alpha-, \beta$-, $\gamma$-ABA were the main products in both hydrolyzed and unhydrolyzed portions, respectively.

Figure 5 shows the ESI-MS spectrum of products of the UV 


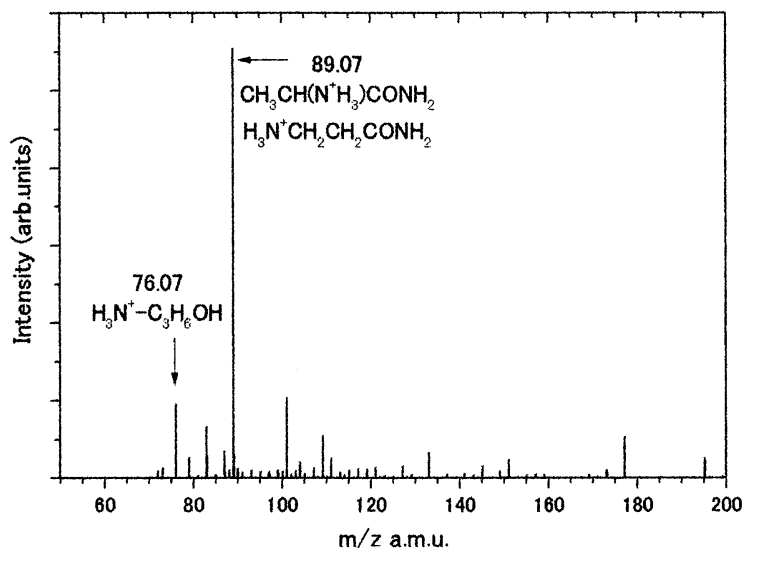

Fig. 5 ESI-MS spectrum of products of the UV irradiation to propanamide aqueous solution with ammonia.

irradiation to the propanamide aqueous solution with ammonia. Molecular ions at 76.07 (aminopropanol) and at $89.07(\alpha-, \beta$ alanine amide) are dominant. The alanine amide ion was uniquely assigned by MS and MS/MS. This ion could be observed owning to the high relative abundance of alanine amide ion, although alanine amide is hardly ionized in ESI-MS.

Even before hydrolysis, $\alpha-, \beta$-Ala is produced in the propanamide aqueous solution without ammonia, but not with ammonia. Thus, for the propanamide aqueous solution without ammonia, formation process, $\mathrm{CH}_{3} \mathrm{CH}_{2}(\mathrm{C}=\mathrm{O}) \mathrm{NH}_{2}+\mathrm{H}_{2} \mathrm{O} \rightarrow \alpha$-, $\beta$-Ala $+\mathrm{H}_{2}$, can be considered. For the propanamide aqueous solution with ammonia $\alpha-, \beta$-alanine amide should be produced, owing to excess ammonia.

In the propanamide aqueous solution with ammonia, $\alpha$-ABA, having one more carbon atom than propanamide, was observed weakly in the hydrolyzed portion. $\alpha$-ABA would be derived from large molecules produced from amino- propanol appeared in Fig. 5. In Fig. 5, a very small peak at $m / z=173.17$, which is also found in the propanol aqueous solution with ammonia, can be observed. If the molecular ions appearing at 173.17 in Fig. 5 are the same ions as those appearing in Fig. 3, the formation process of $\alpha$-ABA is the same as in the propanol aqueous solution with ammonia.

\section{Conclusion}

Formation processes of small aliphatic amino acid formed by UV irradiation to organic molecules in aqueous solution are proposed based on the ESI-MS and MS/MS spectra of photoproducts. For amine solutions, the number of carbon atoms of aliphatic amino acids is affected by the presence of ammonia. In amine aqueous solutions with ammonia, both types of amino acids having the same number of carbon atom as, and having one more carbon atom than the starting amine molecule are formed. The former amino acid formation is related to the polymerized amine molecule having a $\mathrm{C}=\mathrm{N}$ bond The latter amino acid is formed from amino acid amide, which is a precursor of amino acid, via dimerization of amine without a $\mathrm{C}=\mathrm{N}$ bond. For an amine aqueous solution without ammonia, former amino acid formation is suppressed. For a propanol aqueous solution with ammonia, the distribution of amino acids is similar to that in the propylamine aqueous solution with ammonia. However, each formation processes of the obtained amino acids are different. Small aliphatic amino acids in the propanol are formed from amino acid amide via complex amino alcohol molecules. In the amide aqueous solutions, amino acid with the same carbon atom number to reactant with the amide compound was formed from alanine amide observed in ESIMS.

We revealed the formation of chiral molecules as intermediate species in amino acid formation by UV irradiation to achiral molecules in aqueous solution. Using circularly polarized UV, an asymmetric synthesis of amino acid from these chiral molecules at intermediate stage is possible.

\section{References}

1. S. L. Miller, Science, 1953, 117, 528.

2. K. Kobayashi, H. Matuda, K. Ushio, A. Ohashi, H. Yamanashi, T. Kaneko, J. Takahashi, T. Hosokawa, H. Hashimoto, and C. Saito, Adv. Space Res., 2001, 27, 207.

3. Y. Takano, K. Ushio, H. Masuda, T. Kaneko, K. Kobayashi, J. Takahashi, and T. Saito, Anal. Sci. 2001, 17, i1635.

4. M. P. Bernsteln, J. P. Dorkin, S. A. Sandford, G. W. Cooper, and L. J. Allamandola, Nature, 2002, 416, 401.

5. G. M. M. Caro, U. J. Meierhenrich, W. A. Schutte, B. Barbier, A. A. Segovia, H. Rosenbauer W. H.-P. Thiemann, A. Brack, and J. M. Greenberg, Nature, 2002, 416, 403.

6. T. Kaneko, A. Ohashi, and K. Kobayashi, Anal. Sci., 2001, 17, i1643.

7. M. P. Bernstein, S. A. Sandford, L. J. Allamandola, and S. Chang, Astropys. J., 1995, 454, 327.

8. W. A. Schutte, Adv. Space Res., 2002, 30, 1409.

9. G. M. M. Caro, U. Meierhenrich, W. A. Schutte, W. H.-P. Thiemann, and J. M. Greenberg, Astronomy Astrophys. 2004, 413, 209.

10. "Electrospray Ionization Mass Spectrometry", ed. R. B. Cole, 1997, John Wiley and Sons, New York.

11. H. Nakata, Eur. Mass Spectrum., 1999, 5, 411.

12. M. X. Zhao and J. L. Bada, J. Chromatogr., A, 1995, 690, 55.

13. M. K. Mathew and P. Balaram, Mol. Cell. Biochem., 1983, $50,47$.

14. A. Shevhenko, I. Chernushevich, W. Ens, K. G. Standing, B. Thomason, M. Wilm, and M. Mann, Rapid Commun. Mass Spectrom., 1997, 11, 1015.

15. H. P. Fitznar, J. M. Lobbes, and G. Kattner, J. Chromatogr., A, 1999, 832, 123. 